\title{
Evaluating Asynchronous Message Boards to Support Cross- Cultural Communities of High-School Students
}

\author{
Caterina Poggi \\ Department of \\ Electronics and \\ Information - \\ Politecnico di \\ Milano (Italy) \\ poggi@elet.polimi.it
}

\author{
Nicoletta Di Blas \\ Department of \\ Electronics and \\ Information - \\ Politecnico di Milano \\ (Italy) \\ diblas@elet.polimi.it
}

\begin{abstract}
Can online forums effectively support collaboration, discussion, and cultural exchange among high-school students from different countries? We present the data resulting from the analysis of a series of asynchronous message boards used within Learning@Europe, a project where students meet in real time in shared 3D virtual environments, and keep in touch between meetings through online forums. Between March 2005 and December 2006 about 5000 students and 250 teachers from 17 European countries took part in Learning@Europe, posting on a total of 194 forums. Focusing mainly on an in-depth analysis of the first L@E implementation (involving about 1000 students and 50 teachers from 6 European countries), we show how forums can support more or less effectively collaboration and discussion tools, what challenges must be faced, and how the tool's evaluation must take into account the components and set of goals of the entire learning experience.
\end{abstract}

\section{Keywords}

Forum, Message Board, Cross-Cultural, Learning Community, Evaluation, Asynchronous Discussion.

\section{INTRODUCTION AND RELATED RESEARCH}

Web-based communication, with its ability to overcome time and space constraints, offers exciting opportunities to education. This paper focuses on one in particular: can online forums be used for supporting a collaborative learning experience across different countries and cultures? Previous research, described in the remainder of this section, has underlined the potential educational benefits of a similar activity, along with its risks. We propose a tentative answer to this question, basing on the analysis of a series of asynchronous message boards used within Learning@Europe, a project by Politecnico di Milano where students meet in real time in shared 3D virtual environments, and keep in touch between meetings through online forums. Between March and May 2005, about 1000 students and 50 teachers from 6 European countries took part in Learning@Europe, posting over 2,400 messages on 41 different forums. A detailed analysis has been performed on these data. Preliminary results from the following implementations, involving about 4000 users from 17 countries, will also be presented. After briefly describing the forums and their role within the learning experience (details can be found in [3] and [7]), we present the data collected, the analysis techniques and the main results. In the conclusions we draw some general lessons. Learning how to collaborate asynchronously with remote partners, mastering virtual communication and expression are important skills for the $21^{\text {st }}$ Century workplace, and schools and governmental policies are starting to recognize them as such, also in an international perspective. Collaboration is also a potentially very rich opportunity in educational terms. Collaborating with remote peers from different cultures, can offer significant advantages in the development of the students' identity. Identities "must be worked out in practice" [13]: students who work together with foreign peers are involved in a community of practice; it provides exposure to different habits and lifestyles, so that students learn more about who they are also by realizing what they are not: "Non-participation is, in a reverse kind of fashion, as much a source of identity as participation" [13]. On the other hand, collaboration is essential in a Constructivist perspective to provide opportunities for the social negotiation of meaning. According to Vygotsky [11], meaning is a social construct and learning is a social, collaborative process. Learners need a social environment providing alternative views that they can use "to test the viability of their understanding and in building the body of propositions that constitute "knowledge" [1]. Learning happens also through spontaneous group interaction; Daniel et al. [2] for instance classify sociability, sharing experience, peer support, and others as discourse variables 
typical of "incidental learning", whereas inquiry, argumentation, elaboration, clarification, feedback, etc., belong to the "intentional learning" cluster. It is important to note that collaborating online is different from face to face collaboration, for instance in terms of interpersonal skills required: interlocutors cannot rely, as in face to face communications, on visual and auditory cues such as physical appearance, facial expressions, gesturing, intonation, etc. [12]. On one hand, people who are shy, or likely to incur in prejudices based on their personal appearance, can find in a forum a powerful means for expressing themselves. On the other hand, it is more difficult to understand the tone of a message: is the author joking or serious, or even angry? Misunderstandings are frequent, also because - being the forum an asynchronous means of communication - what seems obvious to the sender at the moment of writing may not be equally clear to the reader a few days later. Students therefore must learn to explicit what they are referring to, and need also to practice how to argue a point or disagree with someone without being or sounding aggressive. All of these are valuable skills to learn, and some educators regard the forum as even more effective than face-to-face interaction for supporting this kind of higher-level learning, in that students have the time to reflect upon one's point of view (recorded in a written post) and carefully construct and revise their answer [8]. How can online forums be used effectively for learning, and eventually for creating a thriving community of learners? Setting up an online message board and allowing people to post on it does not make a community. According to Preece [10], designing an online virtual community involves thinking about the people to be reached, the purposes this community would allow them to achieve, and the policies regulating interaction, so that everyone's goals can be more easily achieved. It requires to design a usable infrastructure, and to support sociability: trust needs to be built among users, and the critical mass must be reached, i.e. the number of users that make the community interesting and attractive, without giving the impression of being "lost in the crowd".

\section{LEARNING@EUROPE:AN EDUCATIONAL EXPERIENCE INVOLVING A EUROPEAN ONLINE COMMUNITY}

$\mathrm{L} @ \mathrm{E}$ is structured upon a 6-7 weeks experience: four classes of high school students from different European countries take part in a cultural competition (2 classes against 2). Students meet together on a shared online $3 \mathrm{D}$ environment accessible over the Internet, for four times: four cooperative sessions distributed across two months, each session lasting about one hour. 2 students per class are represented in the 3D world by "avatars" (i.e. graphical human-shaped representations of users, see
Figure 1). Meetings are devoted to cooperative activities, such as discussions and games. All games are based on cultural riddles requiring an accurate knowledge of the subject matter, i.e. the formation of nation-states in European modern history.

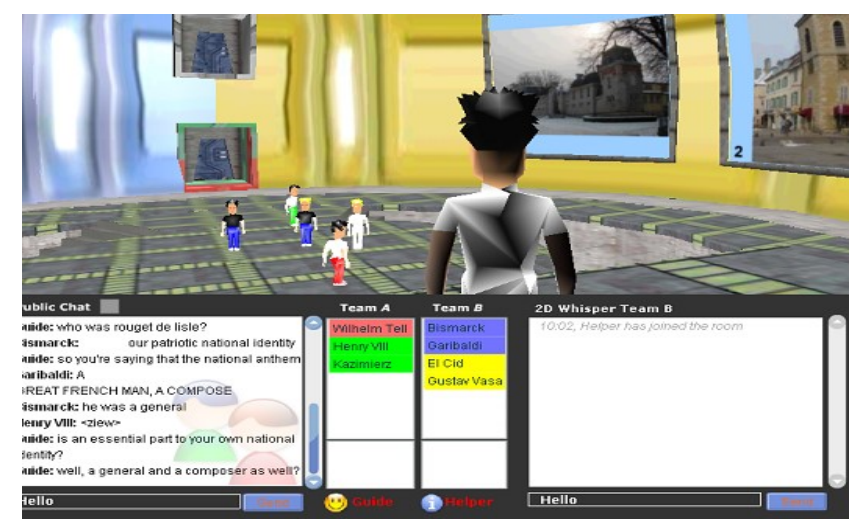

Figure 1. Avatars presenting their towns and countries

Students interact via chat in the 3D world and asynchronously through online forums during the intervals between sessions. The language of all interactions, interfaces, and study materials, is English. Every online cooperative session lasts approximately 1 hour; 10 avatars move around in the virtual world: 8 students (2 per school), a Guide and a Helper, human tutors "physically" present in the virtual world. While two students in each class control an avatar in the 3D world, two more interact with remote peers via the " $2 \mathrm{D}$ chat", a chat panel separated from the 3D graphics); the rest of the class groups around them or follows from a projection screen, taking turns and helping them to answer questions. In order to avoid confusion and waste of time during the session, every single slot of time is dedicated to a precise educational activity, and the Guide makes sure that everyone sticks to it. In the intervals between a session in the virtual world and the following, students are asked to study a set of contents - in the format of interviews to international experts - and to prepare a homework in collaboration with their team members, by doing some research; for example, they may have to analyze the role of languages in the formation of their national identity, and comparing their findings with those of their team partners. Every class can keep in touch with other participants between the sessions and collaborate with them thanks to a set of online forums: the Common Forum is reserved to the 4 classes involved in an Experience, the Team Forum is accessible only to the 2 classes composing a Team, and the Public Forums are visible to everyone: there students and teachers can meet participants in other Experiences, and ask questions about history to the Experts of the Scientific Committee in the Meet the Experts Forum. Below is a schema of the virtual educational experience's structure (Figure 2): 


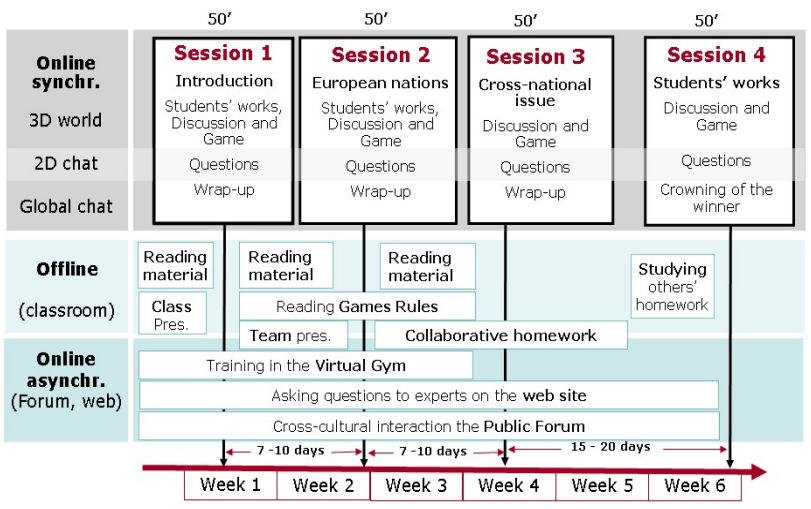

Figure 2. Schema of the educational experience.

In Session 1 students meet each other, and are introduced to the experience. Before Session 2 they have to study material about the history of the four countries involved: the discussion and games of Session 2 are based on this material. They also have to prepare a first team homework (a html team presentation about their national symbols and everyday life) collaborating with their remote partners on the Team Forum. During Session 2 they present their teams, discuss the contents studied, and play a game. They receive a second set of study material for Session 3, which also hosts a discussion and a game. By Session 4, they need to have completed the research homework in collaboration (on the forum) with their team partners; they will present these works during the last online meeting. Guides post on the Common Forum dates and times of online meetings, tasks, instructions and materials, partial scores, announcements and changes of dates. When one or both classes in a team have difficulties accessing the forum, they exchange materials for common assignments via the teachers' emails. Common Forums are moderated by the Guides, Team Forums by the students themselves. Moderators received a short Forum Moderator Manual with instructions and tips on how to perform their role.

\section{DATA COLLECTION AND ANALYSIS}

Between March $1^{\text {st }} 2005$ and December $19^{\text {th }} 2006$, a total of 250 teachers and 5,000 students aged 14 to 19 took part in Learning@Europe, in various phases and in 3 different school years: 2004-05, 2005-06, and 2006-07. They came from 149 high schools in 17 European countries: Belgium, Bulgaria, Czech Republic, Estonia, France, Germany, Greece, Hungary, Italy, Latvia, Lithuania, Norway, Poland, Romania, Spain, Sweden, and UK. In addition to surveys to teachers and students before, during and after the experience, and to a large amount of qualitative data (including the chat logs of every session, all the works produced by students, and videos shot in the classrooms or screen-captured from the Guide's monitor), we collected and archived all the messages posted on the online forums supporting the experience.
Table 1. Learning@Europe: the forums

\begin{tabular}{|l|c|c|c|c|}
\hline & $\begin{array}{c}\text { 2004-05 } \\
\text { March - } \\
\text { May 05 }\end{array}$ & $\begin{array}{c}\mathbf{2 0 0 5 - 0 6} \\
\text { Nov 05- } \\
\text { Jun 06 }\end{array}$ & $\begin{array}{c}\text { 2006-07 } \\
\text { phase 1: } \\
\text { Nov-Dic 06 }\end{array}$ & Total \\
\hline Total forums & 41 & 126 & 27 & $\mathbf{1 9 4}$ \\
\hline $\begin{array}{c}\text { Public forums } \\
\text { (open 3-5 } \\
\text { months) }\end{array}$ & 5 & 6 & 3 & $\mathbf{1 4}$ \\
\hline $\begin{array}{c}\text { Experience } \\
\text { forums } \\
\text { (open 8 } \\
\text { weeks) }\end{array}$ & 36 & 120 & 24 & $\mathbf{1 8 0}$ \\
\hline $\begin{array}{l}\text { Total } \\
\text { messages } \\
\text { posted }\end{array}$ & 2178 & 7215 & 3536 & $\mathbf{1 2 9 2 9}$ \\
\hline Forum users & 222 & 529 & 174 & $\mathbf{9 2 5}$ \\
\hline $\begin{array}{l}\text { Average posts } \\
\text { per forum }\end{array}$ & 53.12 & 57.26 & 130.96 & $\mathbf{8 0 . 4 5}$ \\
\hline $\begin{array}{l}\text { Average posts } \\
\text { per user }\end{array}$ & 9.81 & 13.64 & 20.32 & $\mathbf{1 4 . 5 9}$ \\
\hline $\begin{array}{l}\text { Average views } \\
\text { per post }\end{array}$ & 17.25 & 160.07 & 154.52 & $\mathbf{1 1 0 . 6 1}$ \\
\hline $\begin{array}{l}\text { \% active users } \\
\text { aver }\end{array}$ & $21.14 \%$ & $14.78 \%$ & $27.58 \%$ & $\mathbf{2 1 . 1 6}$ \\
\hline
\end{tabular}

In the first implementation, L@E 2004-05, a supervisor monitored all the forums for the duration of the project, periodically reporting about online activity. 11 reports were produced, recording the increasing numbers of threads, posts, and views, and describing the progression of online collaboration. In addition, Guides were asked to give a subjective evaluation on a 10-points scale of the quality and quantity of messages in their forums according to seven parameters: Socialization, Collaboration, Discussion of Contents, Discussion on L@E, Other Discussions, Moderator, and Problems. They recorded their evaluation of the forums at 4 different times. After the conclusion of the project, all forum posts were saved in archives, and quantitative analysis could be performed on the forum database, which records - with each forum post - information related to the author, the date and time of posting, the forum, the thread, the number of times it was edited, etc. In addition, a more in-depth qualitative analysis was performed on Forum Xp207_TeamB: the most successful Team Forum, not only for the relatively high number of posts (341, an average of 20 posts per user), but for the quality of the interaction and collaboration processes in it. Each message was coded according to the behaviours expressed in the text, categorized in a list adapted from [9]. Additional analysis have been performed on various aspects, including communication flows between individuals and different kinds of groups: the class, the town, the country, the team, Europe. Due to the number of participants in L@E 200506 , it was impossible for one supervisor to follow and 
report about all the 126 forums. Guides completed online weekly reports on each of the Experience forums they moderated, and a final forum report after the conclusion of each experience. L@E staff monitored the Public forums and completed reports about them. In addition, all forum messages were archived in a database with related data (e.g. date and time of posting, author, etc.). Analysis on these data was therefore mainly quantitative. 343 weekly forum reports and 123 final forum reports were collected. The same approach was followed in L@E 2006-07: so far we collected 143 weekly forum reports and 24 final forum reports.

\section{RESULTS OF THE FIRST FORUM IMPLEMENTATION: L@E 2004-05}

At a first glance, participation in the forums seems rather low, considering that the average number of people enabled to access each forum is about 80 students: $78 \%$ of forums count less than 50 posts, with an average of 22.78 posts each (2.64 posts a week, and an average of 408.71 views per forum). The remaining $22 \%$ however have an average of 167.87 posts each (18.91 posts a week, and an average of 1753.75 views per forum).

\subsection{What did not work well...}

Is lack of participation related to problems of usability of the interface? The participants' computer literacy is generally low, and hardly any of them has ever posted in a forum before. According to the preliminary survey on students' expectations, almost half of respondents use computers less than 3 hours a week $(\mathrm{N}=588)$, and about $44 \%$ do not use email; $20 \%$ of teachers use computers less than 3 hours a week, and various messages are clearly experiments of users who wished to see how the interface works, e.g.: "Just wanted to try". Two usability problems may have negatively affected interaction. Some malfunctioning in the "add attachment" function caused delays to team collaboration, whereas in at least 5 different forums students logged in with the account of their teachers, because they couldn't use their own - and in a few forums they did not log in at all until the staff checked all their accounts. In most cases login problems were simply due to students' typing errors. Yet, if the login interface is not fault-tolerant, usernames should be kept simple. Simple errors probably due to lack of expertise, such as posting the same message more than once, or requiring students to edit their message, are quite frequent among the first posts of each forum. However, they decrease considerably with time: this suggests that inexperienced users learn how to use the forums with practice - which in terms of educational goals is certainly a benefit. Usability supports rapid learning, high skill retention, and low error rates [13]. In many cases problems have been a spur for the students, who searched for alternative solutions, or got help from their partners. A possible reason for low participation might be limited access to Internet facilities. An analysis of the Teachers' Surveys responses concerning usage of the forum, crosschecked with the times of posting in Team forums (we assumed that messages posted between 8 a.m. and 1 p.m. had been sent from school, and after 5 p.m. at home. For messages posted between 1 and 5 p.m. we relied also on their content), reveals that the majority of students can access the forums from school. Yet, the ideal scenario of use - the class in the computer lab every week, plus students connecting more frequently from home occurred only in $12.5 \%$ of classes. In addition, in 2 classes (both in the same school) students accessed their Team Forum only from home, and 4 classes never managed to access the forum at all (Figure 3).

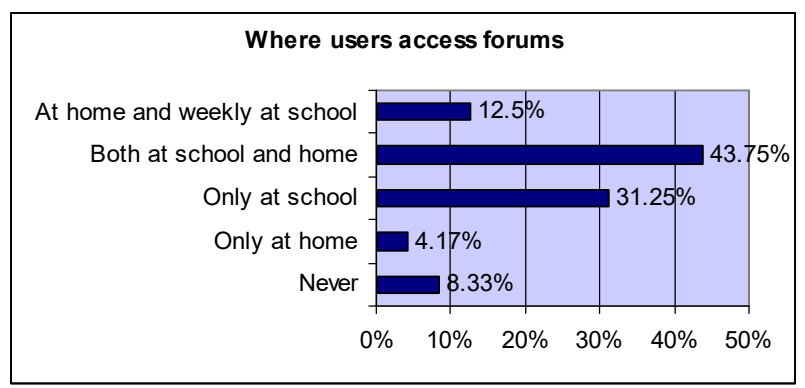

Figure 3. Percentages of classes accessing Team Forums from school and from home

While in the majority of cases students did have access to forums both from school and from home, most did so neither regularly nor frequently. In $68.7 \%$ of classes, teachers did not supervise them - with a perceivable impact in terms of quality and quantity of participation. One reason may be lack of time; a teacher writes: "because lately they have had a difficult period at school (tests and quizzes) they wrote on the forums from their homes." A factor decreasing motivation is the lack of messages from the partner class. A teacher reports: "students were asked to check the forum and take part in it ... but were disappointed of their peer absence." When your remote partners are missing, posting forum messages to the classmate sitting next to you appears rather pointless. An analysis of the forum reports shows that in less than $40 \%$ of Team Forums, both classes managed to complete their two collaborative tasks together, and in $19.1 \%$ of forums there was no real collaboration.

\section{2 ...What was achieved!}

The forums were designed to allow users to keep in contact with remote participants in the intervals between sessions, a need emerged in the testing of SEE, a previous version of this educational experience [3-5]. As additional educational benefits, the forum offered a platform for students to collaborate with their team partners (in SEE all 
exchanges of ideas and materials passed through the teachers' emails), an extra channel for organization and support, and above all a place were cultural discussions started via chat could be resumed in a less hectic environment, allowing time for reflection. Finally, practicing English in authentic contexts and learning how to use this communication technology would be benefits in their own right for many users. Data suggest that, for students who used the forums, most of these benefits were achieved. Analysis of Forum Xp207_B (Figure 4) shows that $34.13 \%$ of posts were related to collaborative tasks: asking and giving information on work progress, attaching documents and proposing ideas, arranging online meetings, etc.

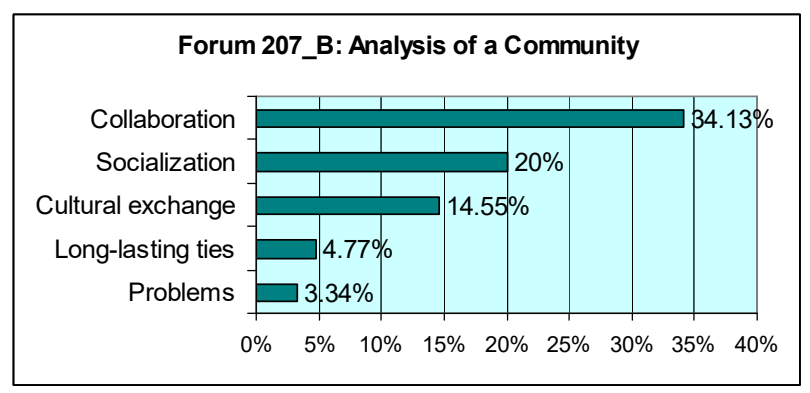

Figure 4. Percentages of behaviours coded for each category (excluding 83 posts of anomalous chat).

The three most active users of this forum, the moderator (an Italian girl) and two Belgian girls, exchanged over 100 friendly messages about themselves and their everyday life, such as: "this morning I went for a ride by bike with a friend, we followed all the wonderful seashore!"; "S. you are so active in your free time!". This off-task informal chatting helped building social ties that smoothened collaboration and lasted beyond the end of the project: toward the end of the experience, users sent at least 20 messages proposing to meet in real life, and exchanging email and instant messaging accounts; messages posted weeks after the last session show evidence that the Belgian and Italian girls did remain in touch even after the end of the school year. Relatively few students and classes took advantage of the possibility of asking questions to a history scholar. However, the quality of the questions posted on the Experts Forum show that students took ownership of what they studied, were curious, and saw the forum as an opportunity to find out more. In 4 questions students re-elaborated some concepts in the study materials and asked the expert if their interpretation was correct. In 6 questions, they identified contradictions in historical phenomena and asked the expert to explain more in depth, e.g. "What if the king (or queen) of England [who is also head of the Church] is a nonbeliever???"). 2 students asked comprehension questions. Finally, 3 questions were unrelated to the study material. but showed the students' interest for their own past and their reliance on the Experts Forum for fast and accurate historical information. Students learnt much about each other's countries, lifestyles and traditions just through social interaction. Some very interesting crosscultural exchanges took place, especially on the Public Forums - where students of all 6 participating countries could meet. Discussion topics in one of the Public Forums ranged from summer holidays (16 posts) to world news, such as Pope John Paul II's funerals (19 posts) to foreign languages in Europe (51 posts). Students had a chance to see how differently people faced the same issue in various countries, for example comparing the different reactions to the Pope's death in different countries (crowds of mourners in Rome, memorial ceremonies everywhere in Poland, nothing at all in France). Students had a chance of being exposed to "other ways of doing things, other enterprises, other practices, and other communities" [13], of seeing what is different and what is "the same" for all.

\subsection{A glance at the experience as a whole}

When asked to evaluate the forums, the Guides gave rather low ratings: the average global score is 2.92 on a 5points scale, where $1=$ very poor, $3=$ acceptable and $5=$ very good. Teachers seem to have a better opinion of the forums: they rated them in average 3.82 on a 5-points scale. The forums are most active before Session 2 and Session 4, when students are requested to use them for team tasks. Those who express low satisfaction, mainly complain about lack of participation from their partners. A teacher commented: "These forums don't work well because the participation of the Italian class is very poor. They can only go online once a week on Thursday for 1 hour!"'. When comparing Learning@Europe's overall educational impact to the teachers' ratings of the forums, online sessions, and study materials, it is interesting to note that most teachers rated the overall impact significantly higher than each of $\mathrm{L} @ \mathrm{E}$ features: for example, the 15 teachers who rated the forum 3 , gave in average more than 4 to the educational impact. The students' improvements as reported by teachers are also much higher than the ratings assigned to project's components: about $60 \%$ of teachers rate their students' improvements in the understanding of history "high" or "very high". Above-average improvements rise to $75 \%$ for functional English skills, $88 \%$ for the use of technologies in learning, and $95 \%$ for group work $(\mathrm{N}=44)$. In addition, $79 \%$ of students are reported to have shown a high or very high increase of respect and curiosity for other cultures: interacting and making friends with people from different countries is an effective way of improving respect and curiosity for these people and their nations. Since teachers evaluate the educational impact of the experience as a whole, it is difficult to determine the specific role of the forums in terms of learning. However, they certainly helped those who used them to achieve the educational 
benefits described above, as documented in the following message: "In these days we have known each other better and we have found out many things in common! We love sports and music even if Italian music and sports are different from the Belgian ones. Anyway we are becoming a united team and interact a lot thanks to the forum and the use of English!"

\section{RESULTS OF 2005-06 AND 2006-07 IMPLEMENTATIONS}

Data from the two following implementations of Learning@Europe seem to confirm the results outlined in the previous paragraphs.

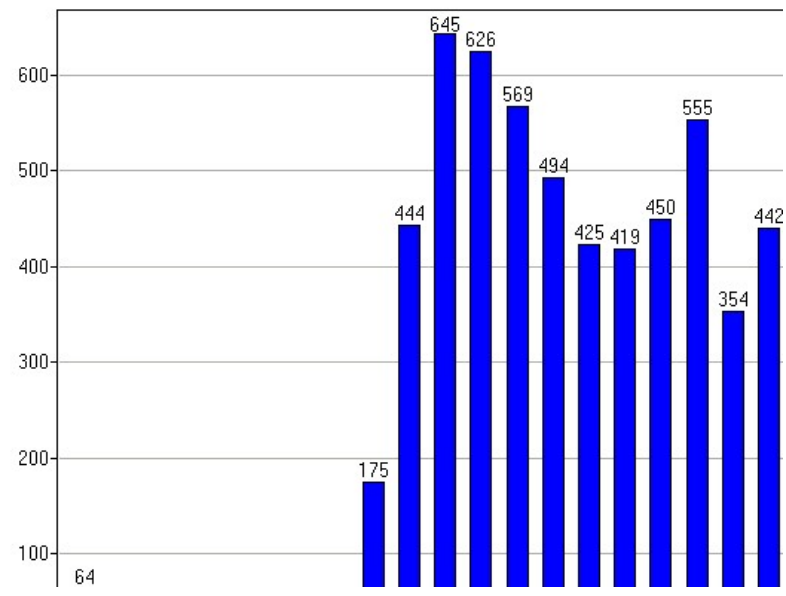

Figure 5. Hours of usage of all 126 forums in L@E 2005-06. The height of the bars represents the number of messages posted in each hour of the day.

While only a minority of students takes advantage of the forum, their activity is often sufficient to guarantee a good amount of learning for those who write, and also to some extent for those (many more) who read. With respect to L@E 2004-05, access to the forums seems in general less of a problem. Figure 5 shows peak hours of forum activity between 10:00 and 12:00, therefore during school lessons, and between 18:00 and 19:00, probably from home. Although participation in the public forums was quite active, collaboration in Team forums - where users of two classes are expected to collaborate for the homework was much more difficult to achieve. Only $17 \%$ of teams managed to collaborate for the homework, and $64 \%$ failed to deliver a complete assignment $(\mathrm{N}=112)$. This is probably among the main reasons why the guides rated the overall forum experience in L@E 2005-06 low: in average 2.02 on a 5 -points scale $(\mathrm{N}=112)$. The teachers, as usual, were more positive: their average rating is $3.35(\mathrm{~N}=108)$. In L@E 2006-07, with less participants at a time and a refined organizational workflow, it was easier to offer support to everyone, keep track of every class' situation and send reminders whenever needed. Collaboration was successful in $34.8 \%$ of teams, and only in $18.75 \%$ of teams one class did not do its part $(\mathrm{N}=23)$. Guides wrote more frequently reports such as " $A$ very good cooperation in homework: they shared the drafts, added comments, asked for integrations or agreement about pictures. A good team-work!", and rated the overall forum experience in average 3.38 on a 5 -points scale $(\mathrm{N}=24)$. Teachers' average rating again was higher: $3.41 \quad(\mathrm{~N}=29)$. Consistently through the 3 years, remote collaboration between two classes via asynchronous message boards emerges as one of the most challenging tasks (Figure 6).

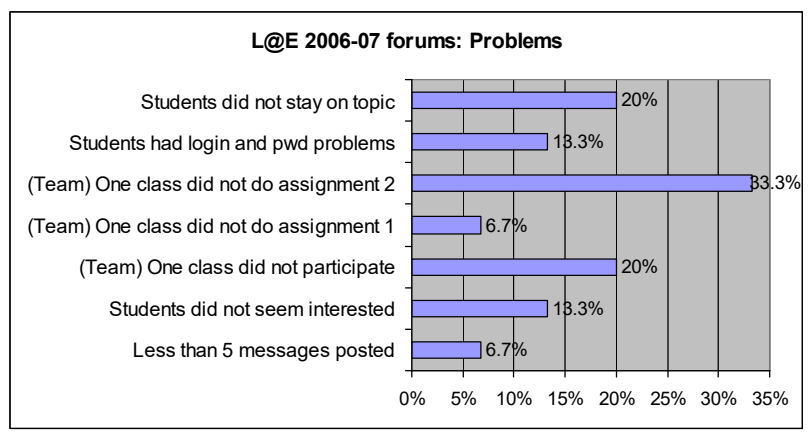

Figure 6. Problems reported in the final reports on L@E forums 2006-07. Total respondents: 15 .

While students did not always manage to use the forums for completing assignments, nor for discussing history, they certainly enjoyed using them for social purposes (see Figure 7). Discussion topics include: self-presentations, free time, past session, next session, each other's cultures, how they are, where they are from, what are their interests, their zodiac signs, music, homework, what they did during the weekend, school, their habits, TV series, school exchange programs, and so on.

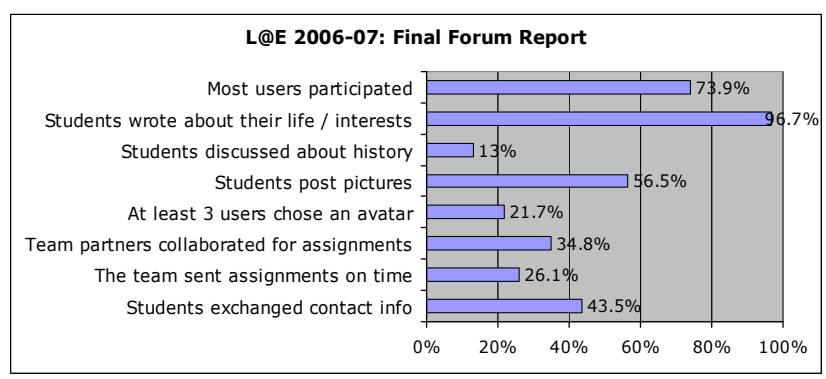

Figure 7. Results from the guides' reports on L@E experience forums 2006-07. Total respondents: 23.

Team spirit grows stronger through forum interaction. Also, students appointed as managers of the Team Forum generally did a very good job. A guide-moderator reported: "Both team asked about the scores and posted messages to cheer or to boost the enthusiasm for next session 3 and will to win. After session 3 team manager A (polish) wrote as usual students' immediate feedback saying the class enjoyed very much the session". Students posted pictures of their class, their country, their capital. A Latvian student from Team B wrote concerning the 
national heroes of team A: 'Hello, friends! Your homework is very exciting... The pictures are really beautiful. [...] Have you heard about our national hero? It is Lachplesis!". The guide adds that "he noticed that everyone is proud of national heroes and that this is the main thing in common among different countries." As for the Experts Forum, in L@E 2005-06, with over 3000 potential users and low moderation, 20 questions were posted in 4 months. In L@E 2004-05, with a more active moderator and about 1000 potential users, only 15 questions were posted over 7 months. In L@E 2006-07, with about 600 users and a relatively responsive moderator, 20 questions were posted in the first 3 months. Data suggest that the number of questions to be expected is rather low. However, the level of questions is generally quite good, and the experts' answers are interesting. The kinds of questions asked indicate that students rely on the experts for asking not just about facts or additional information, but especially about causal relationships, and seem quite interested in the expert's opinion about their own interpretation of historical events. The limited number of questions should not be intended as a sign of low interest; instead, it is important to underline the questions' quality: a result of the students' reflections. Finally, 1871 messages were posted in the main Public Forum of L@E 2005-06. The "L@E online community" public forum of L@E 2006-07 counts already 1868 messages at the time of writing (March 2007), and it will stay open for another 3 months. One reason for the highly intense activity of L@E 2006-07 might be the active participation in the very first phases of the forum's opening. Differently from the previous years, when students only accessed the forums after Session 1, they received access to the forums one week before the first online meeting; they were strongly encouraged by guides (who were in direct contact with teachers, and could therefore follow classes more closely) to send selfintroductory messages; the forum was actively moderated. As the moderator of the public forum commented, "The topics about history are never the most popular among students, but someone is willing to talk about it!". Although very few threads address history topics directly related to L@E contents, many interesting discussions show the opinions and perspectives of students across Europe about relevant issues. For example, a Latvian student reported about a recently approved law in Russia, allowing the military to "blow up" airplanes taken over by terrorists, regardless of innocent people aboard. A German girl replied that a similar law had been abolished in her country. When students talk about their holiday destinations, the typical foods and the places to visit in their countries, they tend sometimes to become promotional - engaging in discourse more akin to a travel agent than to someone studying European culture! However informal, though, this is also a way to express one's national identity, which certainly captures the interest of foreign peers. Other discussions, describing the everyday life of students, their hobbies and interests, can all be seen in terms of offering an opportunity to create virtual communities of European students: at the very minimum, students have a chance to see that other young people around Europe have similar interests, like the same things (music, movies, sports, books, holidays), debate the same issues (restrictions about alcohol, smoking, driving). Overall, more than $75 \%$ teachers find forums sufficiently effective, good, or very good (Figure 8).

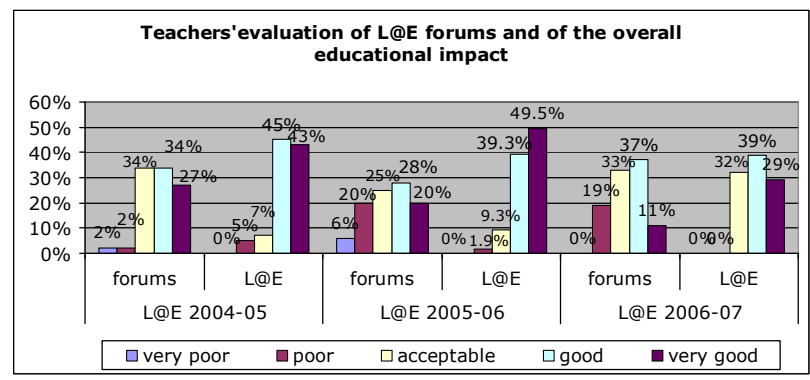

Figure 8. Teachers' evaluation of the forums and of L@E's overall educational impact in L@E 2004-05 (44 respondents), 2005-06 (108 respondents) and 2006-07 (30 respondents).

\section{DISCUSSION AND CONCLUSIONS}

This paper described how online asynchronous forums are used to support learning within a larger educational experience, involving 3D virtual worlds and about 5,000 high-school students from 17 different countries. Quantitative analysis of the data collected from 194 forums, and in-depth qualitative analysis of one of them, show negative and positive outcomes. Although participation was generally low, when forums are considered within the entire learning experience, they result to offer a significant contribution to the overall educational impact of the project. A few general lessons could be drawn from our experience, please note that our suggestions refer to blended "experiences" having an educational goal and in which forums are but one of the components. Our main observation is that although cooperation (in the sense of performing a task together ex. a homework) is very difficult to achieve, forums do serve other purposes that strongly contribute to the achievement of educational benefits. Therefore they are a very recommendable feature, for the following reasons:

- they allow an in-depth collective reflection on cultural issues

- they support intercultural exchanges

- they support a direct contact between learners, tutors and experts (ex. in the experts forum)

- they allow the creation of social bonds that are a value per se and motivate involvement in learning activities. Our suggestions in order to achieve an educationally effective use of forums are the following: 
- closely monitor the forums (even those directly moderated by the users), for 2 reasons:

- Since cooperation and collaboration are crucial, it is very important to discover whether some of the parties are not active and immediately send (via other means: mail or telephone) reminders to participate.

- It is important to check the moderator's work and replace non-motivated moderators.

- Allow time (more than in face-to-face situations; see [9]) and opportunities for socialization: although not strictly related to the educational topic, they are fundamental for building trust and creating bonds.

- Give clear, precise tasks so that users do not spend their time figuring out what to do but are immediately challenged by attractive topics, interesting tasks... - If deemed convenient, add an official recognition to forum's participation (like for example scores). This is a further incentive to active participation.

\section{ACKNOWLEDGMENTS}

The authors wish to thank Jenny Preece for her precious help with the research and analysis of online communities and all the people and institutions that cooperated to create Learning@Europe: Accenture International Foundation, Fondazione Italiana Accenture, and our wonderful staff. Their names can be all found on L@E website: www.learningateurope.net.

\section{REFERENCES}

[1] S. Barab, M. Thomas, T. Dodge, R. Carteaux, and H. Tuzun, "Making learning fun: Quest Atlantis, a game without guns", Educational Technology Research and Development, 53(1), 86-107, 2005.

[2] B. Daniel, R. Schwier, and H. Ross, "Intentional and Incidental Discourse Variables in a Virtual Learning Community", in G. Richards (Ed.), Proceedings of World Conference on E-Learning in Corporate, Government, Healthcare, and Higher Education 2005 (pp. 1953-1965). Chesapeake, VA: AACE, 2005.

[3] Di Blas, N., Gobbo, E., \& Paolini, P. (2005). 3D Worlds and Cultural Heritage: Realism vs. Virtual Presence. In J. Trant and D. Bearman (Eds.), Museums and the Web 2005: Proceedings. Toronto, Canada: Archives \& Museum Informatics

[4] Di Blas, N., Paolini, P., \& Poggi, C. (2003). SEE (Shrine Educational Experience): an Online Cooperative 3D Environment Supporting Innovative Educational Activities. Proceedings of ED-MEDIA 2003. World Conference on Educational Multimedia, Hypermedia \& Telecommunications, Honolulu, Hawaii, USA
[5] Di Blas, N., Paolini, P., \& Poggi, C. (2005). Educational benefits: testing and evaluation of a collaborative 3D world. In Proceedings of EDMEDIA 2005 - World Conference on Educational Multimedia, Hypermedia \& Telecommunications. Montreal, Canada: AACE.

[6] J. Preece, B. Nonnecke, and D. Andrews, "The top five reasons for lurking: improving community experiences for everyone", Computers in Human Behavior, 20(2), 201-223, 2004.

[7] Gobbo, E., Poggi, C., \& Torrebruno, A. (2005). "Measuring Educational Benefits of ICT-mediated Cultural Heritage Experiences". Proceedings of Heritage Impact 2005, July 7-9, Brighton (UK).

[8] Hiltz, S. (1995). "Teaching in a Virtual ClassroomTM". International Journal of Educational Telecommunications 1(2/3), 185-198.

[9] Maloney-Krichmar, D., \& Preece, J. (2005). A multilevel analysis of sociability, usability and community dynamics in an online health community. Transactions on Human-Computer Interaction (special issue on Social Issues and HCI), 12(2), 201232.

[10] Preece, J. (2000). Online Communities: Designing Usability, Supporting Sociability. Chichester, UK: John Wiley \& Sons.

[11] Vygotsky, L.S., (1978), Mind in society. Cambridge, MA: Harvard University Press

[12] Walther, J. B. (1992). Interpersonal effects in computer-mediated interaction: A relational perspective. Communication Research, 19(1), 52-90.

[13] Wenger, E. (1998). Communities of Practice. Learning, Meaning, and Identity". Cambridge, United Kingdom: Cambridge University Press. 